University of South Florida

DIGITAL COMMONS

Digital Commons @ University of

@ UNIVERSITY OF SOUTH FLORIDA

South Florida

Fall 2003

\title{
Ocean Observer Study: A Proposed National Asset to Augment the Future U. S. Operational Satellite System
}

John D. Cunningham

Don P. Chambers

University of South Florida, dchambers@marine.usf.edu

Curtiss O. Davis

Andrew Gerber

Rosalind Hetz

See next page for additional authors

Follow this and additional works at: https://digitalcommons.usf.edu/msc_facpub

Part of the Marine Biology Commons

\section{Scholar Commons Citation}

Cunningham, John D.; Chambers, Don P.; Davis, Curtiss O.; Gerber, Andrew; Hetz, Rosalind; McGuire, James P.; and Pichel, William, "Ocean Observer Study: A Proposed National Asset to Augment the Future U. S. Operational Satellite System" (2003). Marine Science Faculty Publications. 203.

https://digitalcommons.usf.edu/msc_facpub/203

This Article is brought to you for free and open access by the College of Marine Science at Digital Commons @ University of South Florida. It has been accepted for inclusion in Marine Science Faculty Publications by an authorized administrator of Digital Commons @ University of South Florida. For more information, please contact digitalcommons@usf.edu. 


\section{Authors}

John D. Cunningham, Don P. Chambers, Curtiss O. Davis, Andrew Gerber, Rosalind Hetz, James P. McGuire, and William Pichel 


\section{Ocean Observer Study: A Proposed National Asset to Augment the Future U.S. Operational Satellite System}

John D. Cunningham

(NPOESS IPO)

Don Chambers (University of Texas-Austin)

Curtiss 0. Davis (NRL)

Andrew Gerber (JPL)

Rosalind Helz (USGS)

James P. McGuire

(NPOESS IPO)

William Pichel (NOAA)

\section{ABSTRACT}

The next generation of U.S. polar orbiting environmental satellites, are now under development. These satellites, jointly developed by the Department of Defense (DoD), the Department of Commerce (DOC), and the National Aeronautics and Space Administration (NASA), will be known as the National Polar-orbiting Operational Environmental Satellite System (NPOESS). It is expected that the first of these satellites will be launched in 2010. NPOESS has been designed to meet the operational needs of the U.S. civilian meteorological, environmental, climatic, and space environmental remote sensing programs, and the Global Military Space and Geophysical Environmental remote sensing programs. This system, however, did not meet all the needs of the user community interested in operational oceanography (particularly in coastal regions). Beginning in the fall of 2000, the Integrated Program Office (IPO), a joint DoD, DOC, and NASA office responsible for the NPOESS development, initiated the Ocean Observer Study (OOS). The purpose of this study was to assess and recommend how best to measure the missing or inadequately sampled ocean parameters. This paper summarizes the ocean measurement requirements documented in the OOS, describes the national need to measure these parameters, and describes the satellite instrumentation required to make those measurements.

\section{INTRODUCTION}

$\mathrm{T}$ The first phase of the Ocean Observer Study focused on trying to determine what operational ocean products were needed by the United States user community. The request for this type of information went to industry, DOA, DOC, DoD, EPA, FEMA, NASA, NIC (National Ice Center), NSF, USCG, USGS, and university personnel who need and use ocean data. Operational users and scientists who submitted product requirements with similar objectives were grouped into teams to develop common requirements. Each team developed one or more Environmental Data Requirement(s) (EDRs). These EDRs (see Table 1 for a list of EDR titles) were collected into a User Requirements Document which was the basis for the Ocean Observer Study. After reviewing the user requirements, it was determined by these teams that no single instrument could satisfy the requirements, and that a suite of instru- ments would be necessary to collect the data needed by the ocean user community. The requirements that could be satisfied by the NPOESS instruments were not addressed further. The unsatisfied requirements became the basis for the Ocean Observer Study. Upon examination of the instruments that would be required to capture these unsatisfied requirements, it was noted that these sensors could also be used for land and hydrologic applications, so the study was expanded to include EDRs related to those applications.

Once the data requirements had been determined, the study proceeded to address instrument designs and mission architecture. The requirement set was then turned over to the engineering group, tasked with developing four different system configurations with cost estimates for each, and the number of data requirements (not which ones) each configuration could satisfy. Since each requirement had an equal weight, the selection of requirements to be satisfied was left to the discretion of the engineering team. The resultant configurations followed an expected trend; the highest cost design would satisfy most of the requirements, with the lowest cost design satisfying the least. An internal review was then held to examine the results in more detail, and it was determined that some of the minor requirements, even though given equal weight in the study, were driving costs. It was concluded that if the weights of some of the minor requirements were reduced, another design could be developed that would be reasonably priced and would still satisfy most of the requirements. The design resulting from this de-emphasis on minor requirements became the fifth design, which proved to be the most cost-effective design. This paper addresses only the system element designs which deal with the fifth design (option 5: Table 2). Option 5 consists of two satellites. One satellite is in an $800 \mathrm{~km}$ altitude sun synchronous polar orbit with an ascending equator crossing time of 1:00 pm, and has a payload consisting of a dual-frequency (C and L band) Synthetic Aperture Radar (SAR) and a high resolution Visible/Infrared Imaging Spectrometer. With this satellite, complete coverage of the Great Lakes and a majority of the U.S. coastal waters is possible every other day. The satellite would be designed to last 7.5 years and a replacement satellite would be launched after 5 years. Every 5 years there would be 2 of these satellites in orbit for 2.5 
years, allowing for more frequent coverage and SAR cross-track interferometry. The second satellite is in a TOPEX orbit of $1336 \mathrm{~km}$ altitude with an inclination of 66 degrees relative to the equator. Its payload is a Wide Swath Altimeter with a central Delayed Doppler Altimeter.

These instruments were chosen for Option 5 because when placed in the orbit configuration identified above, the resultant system has the capacity to meet the requirements of most of the EDRs. The Altimeter addressed Sea Surface Height (SSH) related EDRs. The Visible/Infrared imaging spectrometer addressed the biological processes and sea surface temperature related EDRs, while the SAR addressed those associated with land and ocean physical processes, and geological and biological characterizations.

Table 2 summarizes the five different constellations evaluated during the OOS. Option 5 was selected as the best option and is the focus of the remainder of the study and the subject of this report.

\section{OCEAN OBSERVER INSTRUMENTS}

\section{Altimeter}

\section{Rationale}

Until the 1970s, observations of the ocean variability in deep waters were limited mainly to measurements of temperature and salinity at fixed depths at stations along a ship's track. Although the spacing between stations along the ship's track might be less than a hundred kilometers, spacing between ship tracks might be thousands of kilometers, and the time between regional observations might be years or even decades. Some areas, such as the Gulf Stream, have been sampled regularly, but vast regions of the ocean have been sampled at most once, and more often than not, never.

Combine this lack of sampling with the fact that the ship observations have been taken with a variety of measuring devices with different error characteristics and biases, and that the ship's location on the surface may not be precisely known, and it is easy to understand why global studies of the Earth's oceans have been difficult. At the most, only "steadystate" means, or average monthly variations have been possible over the global oceans with ship data, and many of the values are based on interpolations from data hundreds of kilometers away, or from one or two measurements in a century.

Some insight into the global ocean variability has been gleaned from numerical models. Before altimetry, the results coming from the models could not be considered accu-

Table 1. Ocean Observer Environmental Data Requirements (EDRs)

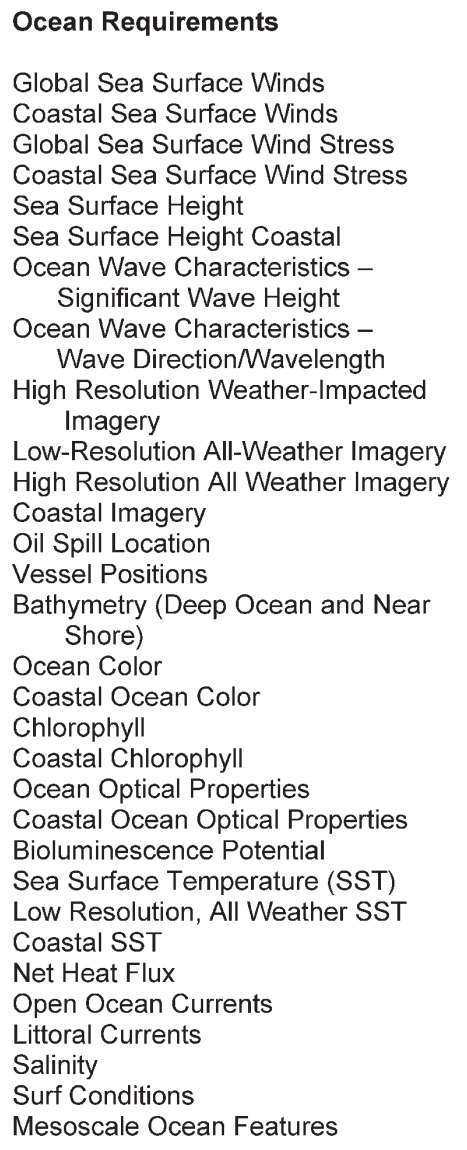

\section{Ocean Requirements}

Significant Wave Height

cean Wave Characteristics -

igh Resolution Weather-Impacted Imagery

Low-Resolution All-

Coastal Imagery

Oil Spill Location

Vessel Positions

Bathymetry (Deep Ocean and Nea Shore)

Chlorophyl

Sea Surface Temperature (SST)

Coastal SST

Salinity

Mesoscale Ocean Features
Coastal Ocean Colo
Cryospheric Requirements

Ice Concentration/Age/Motion/Edge Location

Ice of Land Origin (Icebergs)

Ice Surface Temperature

Sea Ice Freeboard

River Ice Location/Condition

Continental Ice Sheet Melt Zone

Ice-Sheet Motion

Ice-Sheet Grounding Line Position

Sea Ice Characterization

\section{Hydrologic Requirements}

Flood Mapping

Snow Water Equivalent Mapping

Soil Moisture (Surface)

Regional Soil Moisture

Coastal Wetland Mapping

\section{Land Requirements}

\section{Land Surface Topography \\ Land Surface Deformation \\ Land Surface Freeze/Thaw State \\ Vegetation Classification/Biomass \\ Coastal Change}

\section{Atmospheric Requirements}

Mesoscale Atmospheric Features Microscale Atmospheric Features
Glacier Volumetric Change

rate, due to the limited available real data that went into them, and the simplified dynamics that were used to make calculations within a reasonable period of time. More significantly, it was not possible to model long period changes in the ocean associated with climate change, since this requires knowledge of the heat and moisture exchange between the atmosphere and the ocean, both of which were poorly measured.

Thus, it was clear that high precision, global measurements of the ocean for an extended period were needed to improve our models and, consequently our understanding of ocean dynamics and long-term change. It was also determined by the NPOESS team that it would be beneficial if all the measurements were made from a single, stable platform in order to provide the most accurate measurements of long-term change.

\section{Instruments}

A method of obtaining such a data set was proposed in the 1960s. The method involved the use of satellite-based radar altimeters in Earth orbit to measure the distance 
Table 2. Ocean Observer Mission Options Studied

Note: $\mathrm{s} / \mathrm{c}=$ spacecraft, $\mathrm{RPI}=$ Repeat Pass Interferometry, ATI=Along Track Interferometry, CTI=Cross Track Interferometry, WSA=Wide Swath Altimeter $\mathrm{DD}=$ Delayed Doppler Altimeter

\begin{tabular}{|c|c|c|c|c|c|c|c|c|c|}
\hline $\begin{array}{l}\text { Completion Status } \\
\text { JPL - Team X }\end{array}$ & Option & Spacecraft & $\begin{array}{c}\text { Orbit } \\
\text { Altitude } \\
\text { (km) } \\
\end{array}$ & $\begin{array}{c}\text { Orbit } \\
\text { Inclination } \\
\text { (degrees) }\end{array}$ & $\begin{array}{c}\text { Nodal } \\
\text { Crossing } \\
\text { (time) } \\
\end{array}$ & $\begin{array}{c}\text { SAR } \\
\text { (configuration) } \\
\end{array}$ & $\begin{array}{l}\text { Altimeter } \\
\text { (Type) }\end{array}$ & Scatterometer & Ocean Colot \\
\hline Complete & \multirow[t]{2}{*}{ Hi 01} & sic $1 A \& 1 B$ & 800 & 98.6 & $1 \cdot 30$ & $\begin{array}{l}\mathrm{ATI}+\mathrm{CTI}+\mathrm{RPI}+ \\
\text { Quad Pole }\end{array}$ & & + & + \\
\hline Complete & & $8 / 2$ & 1336 & 66 & & & WSA with 00 & & \\
\hline Complete & \multirow[t]{3}{*}{ Hi 02} & $s / c 1$ & 800 & 98.6 & 130 & \begin{tabular}{|r|} 
Single Sided C\&L + \\
ATI + RPI + Ouad Pole
\end{tabular} & & & + \\
\hline Complete & & $8 / 22$ & 1336 & 66 & & & WSA with OD & + & \\
\hline Complete & & $s / 03$ & 1336 & 66 & & & $\mathrm{DO}^{\circ}$ & & \\
\hline Complete & \multirow[t]{2}{*}{ OPT 5} & $s / c 1$ & 800 & 96.6 & $1: 30$ & $\begin{array}{c}\text { Single Sided C\&L + } \\
\mathrm{ATI}+\mathrm{RPI}+\text { Ouad Pole }\end{array}$ & & & + \\
\hline Complete & & $\operatorname{sic} 2$ & 1336 & 66 & & & WSA with DD & + & \\
\hline Complete & \multirow[t]{3}{*}{ Med 01} & $s / c 1$ & 800 & 98.6 & $1: 30$ & $\begin{array}{c}2 \text { Sided C\&L + RPI + } \\
\text { Ouad Pole }\end{array}$ & & & + \\
\hline Complete & & $8 / c 2$ & 1336 & 66 & & & Regular & + & \\
\hline Complete & & $\operatorname{sic} 3$ & 1336 & 66 & & & Regular & & \\
\hline Complete & \multirow[t]{2}{*}{ Low 01} & $s / c 1$ & 800 & 98.6 & $1 \cdot 30$ & $\begin{array}{c}\text { Single-Sided C + Ouad } \\
\text { Pole + RPI }\end{array}$ & & & + \\
\hline Complete & & $s / c 2$ & 800 & 108 & & & Regular & + & \\
\hline \multicolumn{10}{|c|}{ DD* - Regular Alt (JASON II Type) with Delayed Doppler (DD) } \\
\hline & \multicolumn{2}{|c|}{ - Best Orbit for the Scatterometer } & ometer & & & & & & \\
\hline & & & & & & & & & \\
\hline & \multirow{2}{*}{\multicolumn{6}{|c|}{$\begin{array}{l}\text {-sic } 1 \text { A \& s c } 1 B \text { needed for Cross Track luterferometry (CTI) } \\
\text {-sic } 18 \text { does not have a Scaatterometer or Ocean Color lustruments on-beard }\end{array}$}} & & & \\
\hline & & & & & & & & & \\
\hline
\end{tabular}

between the satellite and the ocean surface. If the satellite's orbit could be determined with sufficient precision, it could serve as a platform from which accurate height measurements of the ocean surface could be measured. Although the satellite altimeter cannot measure sub-surface quantities (which a ship can), it can measure variations in sea level over much of the Earth's oceans at a reasonable sample rate, and can make measurements in areas never visited by a ship. Although the ephemeris of early altimeter missions could not be determined to better than several meters, advances in techniques, tracking systems, and dynamical models have led to the determination of satellite ephemeredes with an accuracy at the centimeter level. For the first time, long-wavelength, low frequency variations in the ocean's topography could be observed consistently and regularly, and, perhaps most importantly, at an accuracy comparable to the best in situ measurements.

Currently there are 5 altimeters in space: 2 are in a TOPEX orbit (although the TOPEX/Poseidon ground track has been shifted westward), 2 are in a polar orbit, and one in a Geosat Exact Repeat Mission orbit (which is the same as the SeaSat mission from the late 1970s). The TOPEX orbit was specifically designed to minimize biases resulting from sampling geophysical and oceanographic signals (such as tides), and orbit errors due to surface forces (drag, solar radiation pressure), and gravity. TOPEX data are used as a calibration reference for the other altimeters. Because of the orbit design and accuracy of orbit tracking and scientific instruments, TOPEX Sea Surface Height (SSH) data products are accurate to 3-4 $\mathrm{cm}$ (or better, depending on filtering) and its long-term stability is at least $1 \mathrm{~mm}$ per year. The Altimeters in the TOPEX orbit (TOPEX/Poseidon (T/P) and Jason-1) carry three tracking systems for Precise Orbit Determination (POD): a laser retroreflector used for Satellite Laser Ranging (SLR), a Doppler tracking system (DORIS), and a GPS receiver. The GPS receiver was an experimental system for T/P, but is a primary POD system for Jason-1. The combination of the TOPEX orbit configuration, a concerted effort to improve surface force models and gravity models, and the combined SLR and DORIS tracking led to an unprecedented level of accuracy for the initial data release.

In 2007 the current polar instruments (Envisat, Geosat Follow On) are expected to 
end, with no anticipated replacements. In the 2013-2014 time period, NPOESS is scheduled to carry a single altimeter into a polar orbit. In 2012, the altimetry series for the TOPEX orbit is expected to end. If the Ocean Observer Altimetry portion is launched in the 2009-2010 time period, then the long-term continuity of precision altimetry measurements in a TOPEX orbit could be maintained.

A satellite altimeter basically consists of a radio transmitter which emits very sharp pulses of energy several thousand times per second, a receiver to record the pulse after it has been reflected from the ocean surface, and a clock to record the time between transmission and reception. Several thousand pulses are transmitted each second, and many of these pulses must be averaged together to obtain a smooth estimate of the pulse shape because the instantaneous pulse is the superposition of the scatter from many wave facets on the sea surface. The highest rate sample stored by onboard computer is somewhere between 20 per sec to 10 per sec. These pulses are further averaged over 1 second to obtain a 1 per sec pulse shape from which the time of reception and other quantities are computed. The uncertainty in the shape of the smoothed pulse contributes to the noise of the 1-second altimeter height measurement.

The height measurement is referenced to the center of mass of the satellite's orbit about the Earth. This altimeter height above the sea surface may be converted to a direct measurement of the sea surface height above a reference ellipsoid, if the height of the satellite's orbit (and altimeter) above the ellipsoid is also known.

An altimetry height is computed assuming that the speed of light in the atmosphere is constant. This is not true however, as the water vapor, electron content, and density of the atmosphere lengthen the time of propagation of the radar signal. To correct for the water vapor effect, a microwave radiometer is used. A dual-frequency altimeter is used to correct for the electron content. The altimeter spacecraft proposed will carry a wide-swath altimeter with a swath of $200 \mathrm{~km}$ and a spatial resolution of $14 \mathrm{~km} \mathrm{X14} \mathrm{km.} \mathrm{It} \mathrm{will} \mathrm{also} \mathrm{carry} \mathrm{a}$ delayed doppler altimeter with a swath width of $3 \mathrm{~km}$ and a spatial resolution of $7 \mathrm{~km}$ along its track.

\section{Altimetry Applications}

Altimetry is used to obtain Sea Surface Height (SSH) and Sea State (wave height). As mentioned previously, $\mathrm{SSH}$ is calculated from the range determined from the two-way travel time of the radar pulse and the orbit height. The Significant Wave Height (SWH) is deter-
Figure 1. Basin Scale Variability and El Niño (from TOPEX Altimeter)

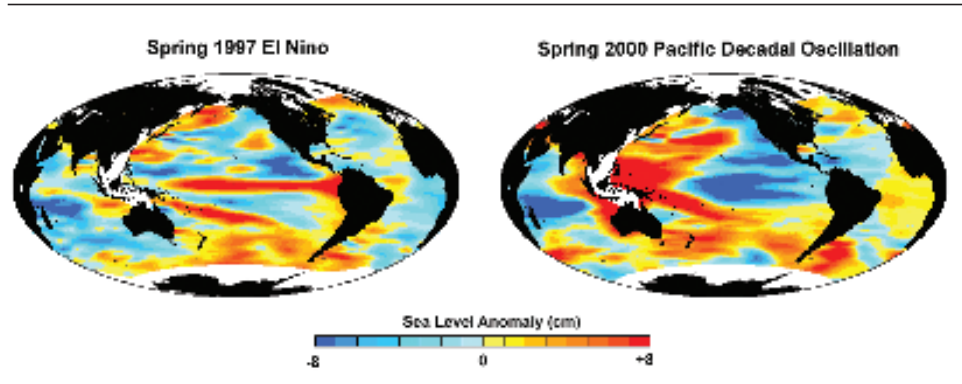

Figure 2. Rate of Sea Level Rise from TOPEX/Poseidon (NEREM, Univ. of Colorado)

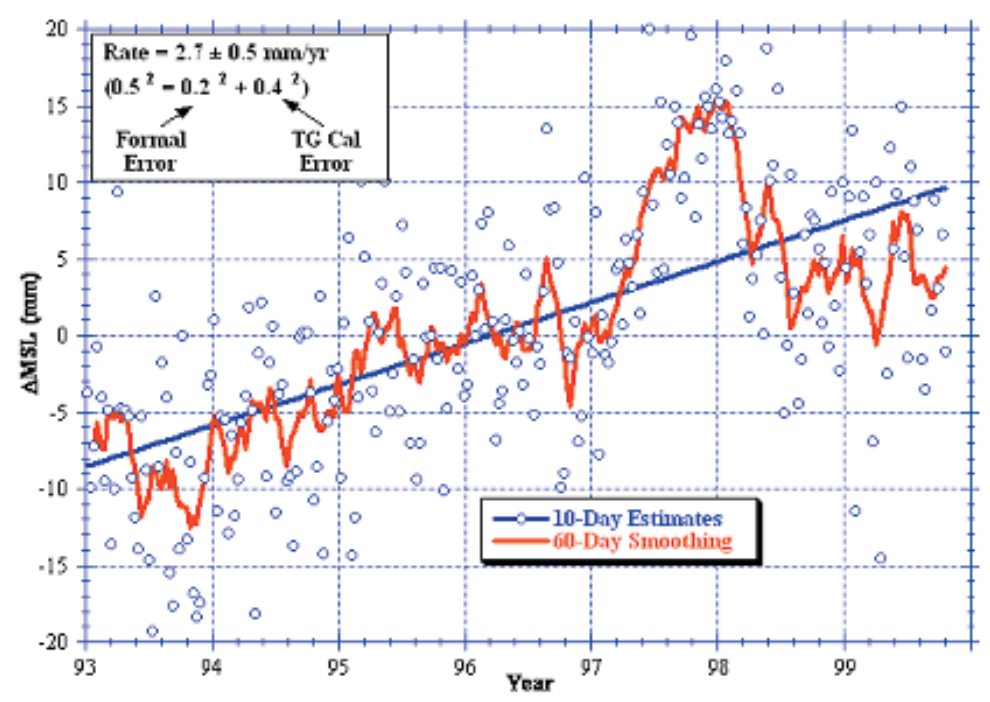

mined from the slope of the leading edge of the returned wave forms; a nearly vertical leading edge indicates small waves, while a sloped leading edge indicates higher waves, as surface waves distort the altimeter pulse (troughs reflect the pulse energy more strongly, while crests tend to disperse the energy). The wind speed can be estimated from the power of the returned pulse (which indicates the amount of scattering at the surface) and statistical models. The average ocean height, or global mean sea level (GMSL) is increasing due to global warming. Water mass is being added from melting glaciers and ice sheets and thermal expansion of the water increases as it retains more heat. Measuring this quantity accurately is important to long-term climate prediction. The rate of this signal is estimated to be at most approximately $2 \mathrm{~mm}$ per year, and small biases or discontinuities in the time series can lead to a GMSL estimation that is significantly larger or smaller than the true rate. Studies have indicated that at least 15 years of continuous altimetry of the quality of TOPEX is necessary to quantify the rate to less than $0.5 \mathrm{~mm}$ per year, because of 
large-scale inter-annual and decadal variations in the ocean such as El Niño (see Figure 1).

In order to quantify the changes of GMSL, which is predicted to be increasing at this time due to global warming (see Figure 2), at least 20-25 years of high quality altimetry without significant biases is necessary. These relatively stringent requirements justify keeping an altimeter in the TOPEX orbit, and to have overlapping measurements with the previous instrument in that orbit, in order to estimate and eliminate systematic errors. This has driven the choice of the TOPEX orbit for the altimeter in the OOS study. NPOESS is in a sun-synchronous polar orbit, which will potentially introduce significant biases into GMSL investigations. However, because of its higher latitude coverage, the NPOESS altimeter could be used to extrapolate the OOS altimeter data to the polar regions.

At atmospheric pressure and at temperatures above 4 degrees $\mathrm{C}$, water expands as it warms, and one of the dominant signals in SSH variability is due to changes in the ocean heat content. Therefore, if one ingests Sea Surface Temperature (SST) data, SSH, and available but sparse in situ measurements into a numerical model, one can obtain a threedimensional thermal picture of the ocean. This information is extremely important to submarine warfare, fishing, and in hurricane predictions (see Figure 3). It is also useful in prediction and determination of El Niño and La Niña events, both extremely important in providing near-term climate forecasts. To improve our near-term climate forecasts and hurricane forecasts, we have chosen a Wide Swath Altimeter for the OOS because it yields higher spatial resolution than currently available altimeters.

One of several components contributing to the ocean's global scale motion is geostrophic circulation. Sea Surface Height can also be used to determine large-scale geostrophic ocean circulation, although this has been limited because it also requires an accurate geoid model, not available until recently. The time-averaged sea surface departs from the geoid by as much as 2 meters over wavelengths larger than $100 \mathrm{~km}$. These deviations, known as the mean dynamic ocean topography, are a result of the large-scale, geostrophic ocean circulation, which balances horizontal pressure gradients.

This relationship, known as the geostrophic balance, implies that large-scale ocean currents will flow along constant pressure contours, with high pressure (high ocean topography) to the right (looking downstream) in the northern hemisphere and to the left in the southern hemisphere. Traditional oceanographic techniques can only determine the
Figure 3. Altimetry Used to Compute Hurricane Heat Potential

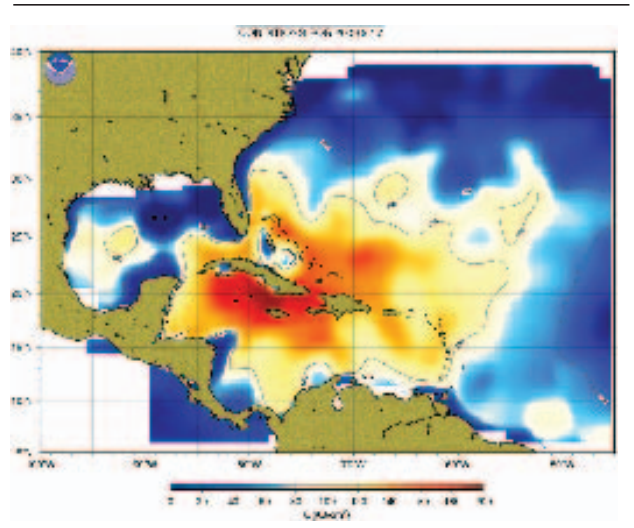

geostrophic current velocity relatively, not absolutely. It can now be determined absolutely using satellite altimeter measurements combined with an accurate geoid. Until recently, geoid errors over the ocean have been $20 \mathrm{~cm}$ or more, which is far higher than the accuracy of SSH from altimetry. A recently released model determined from the GRACE mission has already been shown to be nearly an order of magnitude better than previous models, and forthcoming versions could be close to 100 times better. This means that absolute geostrophic ocean circulation can, for the first time, be accurately computed from altimetry. And, by combining altimetry with in situ measurements, one can obtain the geostrophic velocity at any depth in the water column.

\section{SYNTHETIC APERTURE RADAR}

\section{Rationale}

Synthetic Aperture Radar (SAR) is an essential tool in the national effort to improve the health and security of our nation's citizens and our natural resources, and to protect our environment and our commerce. SAR technologies, including use of multi-frequency (C and L band) and multi-polarization, were developed by DoD and NASA in the 1970s and 1980s. These technologies have been tested on aircraft, satellites (Seasat launched in 1978, but only operational for about 100 days) and on NASA's Space Shuttle (Shuttle Imaging Radar missions A, B, and C/X-SAR and the Shuttle Radar Topography Mission - SRTM). However, the U.S. does not currently have a satellite with a SAR instrument. Research conducted with the SAR data that has been available from the short-duration U.S. missions and from foreign satellites (ERS1/2, Radarsat-1, J-ERS-1, and ENVISAT) has demonstrated the great utility of SAR data in understanding the planet Earth. Federal agencies are increasingly turning to foreign sources 
of SAR data both for all-weather remote sensing imagery and as a technique to precisely detect and define changes of the Earth's surface. The National Ice Center (DoD, NOAA, and U.S. Coast Guard) relies upon Canadian Radarsat-1 SAR imagery to track sea and lake ice cover for the safe navigation of our maritime vessels in the polar regions and on the Great Lakes. NASA and the National Imagery and Mapping Agency (NIMA) used a SAR carried aboard the Space Shuttle (i.e. SRTM) to precisely map the Earth's surface topography with significant benefits to our nation's security. The U.S. Geological Survey (USGS) uses SAR to detect deformation in awakening volcanoes, which threaten our cities and air traffic routes; to measure land movements produced by large earthquakes; and to evaluate the aquifers that store ground water beneath aquifer dependent cities.

\section{Instrument}

A SAR is an imaging radar. Radar systems measure the strength and round-trip time of the microwave signals that are emitted by a radar antenna and reflected off a distant surface or object. The SAR antenna alternately transmits and receives pulses at particular microwave wavelengths (in the range $1 \mathrm{~cm}$ to 1 $\mathrm{m}$, which corresponds to a frequency range of about $300 \mathrm{MHz}$ to $30 \mathrm{GHz}$ ) at one or more polarizations (waves polarized in a single vertical or horizontal plane). For an imaging radar system, about 1500 high-power pulses per second are transmitted toward the target or imaging area, with each pulse having a pulse duration (pulse width) of typically 10-50 microseconds ( $\mu s)$. The pulse normally covers a small band of frequencies, centered on the frequency selected for the radar. Typical bandwidths for an imaging radar are in the range 10 to 200 MHz. At the Earth's surface, the energy in a radar pulse is scattered in all directions, with some reflected back toward the antenna. This backscatter returns to the radar as a weaker radar echo and is received by the antenna in a specific polarization (horizontal or vertical, not necessarily the same as the transmitted pulse). These echoes are converted to digital data and passed to a data recorder for later processing and display as an image. Given that the radar pulse travels at the speed of light, it is relatively straightforward to use the measured time for the roundtrip of a particular pulse to calculate the distance or range to the reflecting object. The chosen pulse bandwidth determines the resolution in the range (cross-track) direction. Higher bandwidth means finer resolution in this dimension.

In the case of imaging radar, the radar moves along a flight path and the area illumi- nated by the radar, or footprint, is moved along the surface in a swath, building the image as it does so.

For a (conventional) Real Aperture Radar ( RAR ) the length of the radar antenna determines the resolution in the azimuth (along-track) direction of the image: the longer the antenna, the finer the resolution in this dimension. In addition, the resolution in azimuth depends also on the range, i.e., on the distance between the SAR antenna and the target: the larger the range, the coarser the resolution. If a RAR were flown on a satellite, then one would need an antenna with a length of several kilometers to achieve a resolution of the order of several tens of meters. Therefore synthetic aperture radars (SARs) are used for obtaining high resolution radar images from space. Synthetic Aperture Radar (SAR) refers to a technique used to synthesize a very long antenna by combining signals (echoes) received by the radar as it moves along its flight track. The aperture is the opening used to collect the reflected energy that is used to form an image. A synthetic aperture is constructed by moving a real aperture or antenna through a series of positions along the flight track.

As the radar moves, a pulse is transmitted at each position; the return echoes pass through the receiver and are recorded in an "echo store." Because the radar is moving relative to the ground, the returned echoes are Doppler-shifted (negatively as the radar approaches a target; positively as it moves away). Comparing the Doppler-shifted frequencies to a reference frequency allows many returned signals to be "focused" on a single point, effectively increasing the length of the antenna that is imaging that particular point. This focusing operation, commonly known as SAR processing, is now done digitally on fast computer systems. The trick in SAR processing is to correctly match the variation in Doppler frequency for each point in the image: this requires very precise knowledge of the relative motion between the platform and the imaged objects (which is the cause of the Doppler variation in the first place).

Synthetic Aperture Radar is now a mature technique used to generate radar images in which fine detail can be resolved. SARs provide unique capabilities as an imaging tool. Because they provide their own illumination (the radar pulses), they can image at any time of day or night, regardless of sun illumination. And because the radar wavelengths are much longer than those of visible or infrared light, SARs can also "see" through cloudy and dusty conditions that visible and infrared instruments cannot. 
Figure 4. Imaging different types of surface with radar

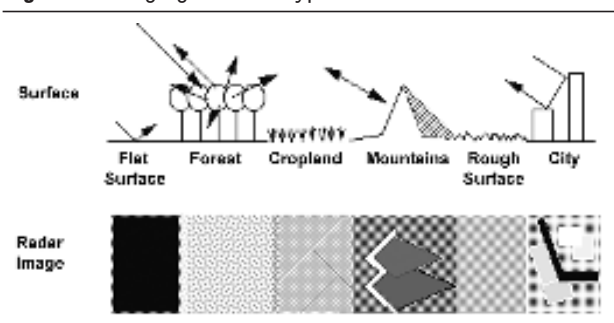

Backscatter of radar for a target area at a particular wavelength will vary for a variety of conditions: size of the scatterers in the target area, moisture content of the target area, polarization of the pulses, and observation angles. Backscatter will also differ when different wavelengths are used. A useful rule-of-thumb in analyzing radar images is that the higher or brighter the backscatter on the image, the rougher the surface being imaged. Flat surfaces that reflect little or no microwave energy back towards the radar will always appear dark in radar images. Vegetation is usually moderately rough on the scale of most radar wavelengths and appears as grey or light grey in a radar image. Surfaces inclined towards the radar will have a stronger backscatter than surfaces that slope away from the radar. They will tend to appear brighter in a radar image. Some areas not illuminated by the radar, like the back slope of mountains, are in shadow, and will appear dark. When city streets or buildings are lined up in such a way that the incoming radar pulses are able to bounce off the streets and then bounce again off the buildings (called a doublebounce) and directly back towards the radar they appear very bright (white) in radar images. Roads and freeways are flat surfaces and appear dark. Buildings, which do not line up so that the radar pulses are reflected straight back, will appear light grey, like very rough surfaces (see Figure 4).

Backscatter is also sensitive to the target's electrical properties, including water content. Wetter objects will appear bright, and drier targets will appear dark. The exception to this is a smooth body of water, which will act as a flat surface and reflect incoming pulses away from a target; these bodies will appear dark. Backscatter will also vary depending on the use of different polarization. Different observations angles also affect backscatter. Track angle will affect backscatter from very linear features: urban areas, fences, rows of crops, ocean waves, and fault lines. The incidence angle, i.e., the angle between the incident radar beam and the normal of the Earth's surface, will also cause a variation in the backscatter: low incidence angles (perpendicular to the surface) will result in high backscatter; backscatter will decrease with increasing incidence angles.

SAR measurement strategies combine radar images of the Earth's surface using different radio frequencies and geometries of observation. Modern SAR satellites precisely measure thousands of square miles in a very few minutes. The resolution of the technique is a function of the wavelength, bandwidth, aperture size, and the power of the transmitted pulses. SAR data can be acquired with great reliability to enable precision-monitoring of surface processes. For example, by combining SAR images taken at different times using interferometric techniques, differences in land surface elevation due to the pumping of underground water or oil, or the intrusion of new magma beneath a volcano can be measured to a few millimeters (less than half an inch) over hundreds of square miles-and this level of detail can be resolved from satellites several hundreds of miles away.

Interferometric SAR (InSAR) is based upon the principle of determining the differences between two SAR images of the same area. For geodetic InSAR measurements, the differencing reveals the changes in the Earth's surface, which occurred between the capture of two radar images with resolution of a fraction of the short radar wavelength. An added feature of this technology is that new research efforts are showing that utilization of polarization information in the radar signals improves the ability to resolve surface characteristics.

SAR imagery from foreign sources is presently being used by NOAA, USGS, the Federal Emergency Management Agency (FEMA), the U. S. Army Corps of Engineers (USACE), the National Science Foundation (NSF), NASA, and other civilian and DoD agencies.

The SAR chosen in Option 5 of the Ocean Observer Study has two frequencies (C and L bands) that can be operated simultaneously or independently. Single, dual, or quad polarization can be chosen independently for each frequency. The system can do the following types of interferometry: along-track (for ocean currents or moving target detection), repeat-pass (for change detection), or crosstrack (for digital elevation calculation). The system can be operated in numerous beam modes allowing a range of resolutions from $5 \mathrm{~m}$ to $100 \mathrm{~m}$ with swath coverages ranging from 30 $\mathrm{km}$ to $600 \mathrm{~km}$. The satellite can be rolled to change the direction of imaging from right to left with respect to the satellite velocity vector. The $\mathrm{C}$ band modes of operation are summarized in Table 3, and the $\mathrm{L}$ band modes of operation are summarized in Table 4 . 
Table 3: Option 5 C-Band SAR Imaging Modes

\begin{tabular}{|c|c|c|c|c|c|c|c|c|c|}
\hline Mode of Operation & $\begin{array}{c}\text { C- } \\
\text { Standard } \\
\text { Mode 1a- } 1 \mathrm{HH} \\
\text { \& VV) or } \\
\text { (HH,HV or } \\
\text { VV, VH) }\end{array}$ & $\begin{array}{c}\text { C- } \\
\text { Standard } \\
\text { Mode } 1 \mathrm{~b} \text { - } \\
\text { (HH or VV) }\end{array}$ & $\begin{array}{c}\text { C- } \\
\text { Standard } \\
\text { Mode 16. } \\
\text { (HH, HV, } \\
\text { WV, VH) }\end{array}$ & $\begin{array}{c}\text { C- } \\
\text { Wide Scansar } \\
\text { Mode } 2 \mathrm{a} \cdot(\mathrm{HH} \& \\
\text { (V) }\end{array}$ & $\begin{array}{c}\text { C- } \\
\text { Wide Scansar } \\
\text { Mode } 2 \mathrm{~b}<\mathrm{HH} \\
\text { or VV) }\end{array}$ & $\begin{array}{c}\text { C- } \\
\text { Narrow Scansar } \\
\text { Mode } 3 \mathrm{a} \cdot(\mathrm{HH} \& \\
\mathrm{W}) \text { or }(\mathrm{HH}, \mathrm{HV} \text { or } \\
\text { W, } \mathrm{VH})\end{array}$ & $\begin{array}{l}\text { C- } \\
\text { Narrow Scansar } \\
\text { Mode 3b -(HH or } \\
\text { VV) }\end{array}$ & $\begin{array}{l}\text { C- } \\
\text { Narrow Scansar ATI } \\
\text { Mode } 3 \mathrm{C} \cdot(\mathrm{HH} \text { or } \mathrm{VV})\end{array}$ & \begin{tabular}{|c|} 
C- \\
Fine Mode \\
4-(HH or VV)
\end{tabular} \\
\hline Resolution- multilook (m) & 25 & 25 & 26 & 100 & 100 & 50 & 60 & 250 & 5 \\
\hline Ground8wath (km) & $\begin{array}{l}\text { i) } 150 \cdot 130 \\
\text { ii) } 150\end{array}$ & 150 & 100 & 600 & 600 & 350 & 350 & 150 & 30 \\
\hline Number of Looks & 4 & 4 & 4 & $10-18$ & $10-20$ & $4 \cdot 7$ & $4 \cdot 7$ & $118-164$ & 2 \\
\hline Field of Viewfrom Nadir (Inc. Angle) & $\begin{array}{l}\text { i) } 16 \cdot 40^{1} \\
\text { ii) } 15 \cdot 53^{1}\end{array}$ & $15 \cdot 53^{9}$ & $15-40^{4}$ & $15-54^{0}$ & $15-54^{0}$ & $15-54^{1}$ & $15 \cdot 54^{0}$ & $15-26^{n}$ & $15-60^{3}$ \\
\hline Polarizations & $\begin{array}{l}\text { i) HH \& V } \\
\text { in HH, HV or } \\
\text { VV, VH }\end{array}$ & $\mathrm{HH}$ or VV & $\begin{array}{c}\text { HH, HV, VV. } \\
\text { VH }\end{array}$ & $\mathrm{HH} \& \mathrm{VV}$ & $\mathrm{HH}$ or $\mathrm{V}$ & $\begin{array}{l}\text { 1) HH \& VV } \\
\text { ii) HH, HV or VV, } \\
\text { VH }\end{array}$ & HH or VV & HH or WV & $\mathrm{HH}$ or $\mathrm{VV}$ \\
\hline
\end{tabular}

Table 4: Option 5 L-Band SAR Imaging Modes

\begin{tabular}{|c|c|c|c|c|c|c|c|c|}
\hline Mode of Operation & \begin{tabular}{|c|} 
L- \\
Standard \\
Mode 1a-4HH \& \\
VV) or (HH,HV \\
or VV,VH)
\end{tabular} & $\begin{array}{l}\text { L-split spectrum } \\
\text { Mode } 1 \mathrm{~b}-(\mathrm{HH} \text { or } \\
\mathrm{W})\end{array}$ & $\begin{array}{l}\text { L. } \\
\text { Standard } \\
\text { Mode 16- } \\
\text { (HH, HV, } \\
\text { WV, VH) }\end{array}$ & $\begin{array}{c}\text { L. } \\
\text { Wide Scansar } \\
\text { Mode 2-(HH or } \\
\text { VV) }\end{array}$ & $\begin{array}{c}\text { L- } \\
\text { Narrowr Scansar } \\
\text { Mode Ja-(HH \& } \\
\text { VV) or }(\mathrm{HH}, \mathrm{HV} \text { or } \\
\text { VV,VH) }\end{array}$ & \begin{tabular}{|c|} 
L. \\
Narrows Scansar \\
Mode Jb-(HH or \\
VV)
\end{tabular} & \begin{tabular}{|c|} 
L. \\
Narrow Scansar ATI \\
Mode Jc-(HH or VW)
\end{tabular} & $\begin{array}{c}\text { L. } \\
\text { Fine Mode 4- } \\
\text { (HH) }\end{array}$ \\
\hline Resolution- multilook (m) & 25 & 25 & 25 & 100 & 50 & 50 & 250 & 10 \\
\hline GroundSwath (km) & $150-130$ & $150-130$ & $150 \cdot 130$ & 600 & 350 & 350 & 100 & 30 \\
\hline Number of Looks & 4 & 4 & 4 & $10 \cdot 19$ & $4 \cdot 7$ & $4 \cdot 7$ & $\begin{array}{l}\text { i) } 148 \cdot 176 \\
\text { iii) } 88-68\end{array}$ & 2 \\
\hline Field of Vlewtrom Nadir (inc. Angle) & $15-40^{0}$ & $15-40^{6}$ & $15-40^{9}$ & $15-54^{0}$ & $15-54^{6}$ & $15-54^{0}$ & $15-22^{4}$ & $15-49^{*}$ \\
\hline Polarizations & $\begin{array}{l}\text { i) } \mathbf{H H}, \mathrm{VV} \\
\text { ii) } \mathrm{HH}, \mathrm{HV} \text { or } \\
\mathrm{V}, \mathrm{VH}\end{array}$ & $\mathrm{HH}$ or $\mathrm{VY}$ & $\begin{array}{c}H H_{2}, H V, V V_{1} \\
\text { VH }\end{array}$ & HH or VV & $\begin{array}{l}\text { i) } \mathrm{HH} \& \mathrm{VV} \\
\text { ii) } \mathrm{HH}, \mathrm{HV} \text { or } \\
\mathrm{V}, \mathrm{VH}\end{array}$ & $\mathrm{HH}$ or $\mathrm{VW}$ & HH or VV & $\mathrm{HH}$ \\
\hline
\end{tabular}

\section{SAR Application - Shallow Water Bathymetry}

The medium and fine-scale features of the ocean bottom in shallow water is mirrored in surface roughness variations caused by tidal flow and associated wave spectral changes over shallow areas. A comparison of the lighter patterns from bottom-reflected light in a photograph with the roughness variations in an SAR image demonstrates that underwater shoals having depths from perhaps $5 \mathrm{~m}$ to $50 \mathrm{~m}$ are imaged with SAR via surface roughness and radar backscatter variations. There is a successful quantitative theory for this process that uses a Boltzmann-like equation to describe the changes to the surface wave spectrum that lead to the signatures.

\section{SAR Application - Oceans}

SAR observations of the oceans contain abundant information on both coastal and deep-ocean physical processes important to weather forecasting, the management of marine resources, pollution control, and safety of navigation.
SAR images display signatures that discriminate important air-sea interaction processes due to its sensitivity to small-scale changes in surface roughness. Although the roughness modulations are often small (on the order of the radar wavelength, i.e., several centimeters), they nevertheless are quite apparent in the imagery and often mirror significant and extensive ocean as well as atmospheric dynamics. For example, it is the interface between the atmosphere and the upper ocean that establishes the interchange of heat, momentum, and moisture in both the lower and the upper atmosphere. It is those fluxes that must be determined if we are to understand and introduce into our weather prediction models the ability to better predict air temperature, humidity and cloudiness as well as the longer term effects of carbon dioxide sequestration.

Much, if not most of the air-sea interchange occurs episodically during storms and high-wind events. During these events, the surface of the sea is hidden from remote sensors operating in the visible and infrared portions of the electromagnetic spectrum due to cloud cover. Furthermore, ship and buoy-based meas- 
Figure 5. Hurricane Bonnie, August 31, 1998: The left image is a composite of Geostationary infrared imagery and Radarsat-1 SAR imagery of Hurricane Bonnie. The right image shows details of the SAR image showing the eye of the hurricane, rain bands, and convective cells. SAR imagery copyright Canadian Space Agency, 1998.
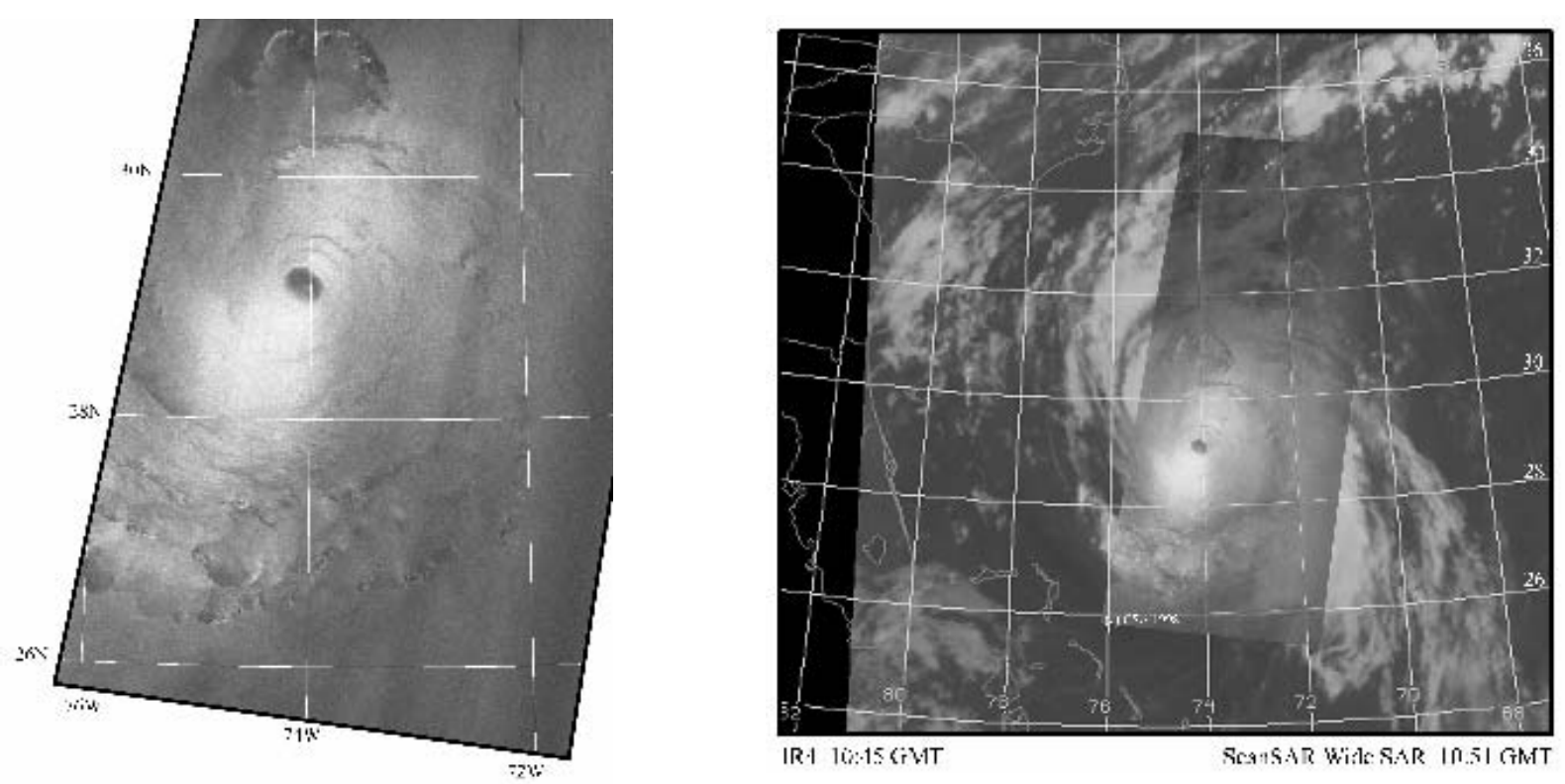

urements are more limited or even compromised during such heavy weather episodes. Thus, it is not possible to make accurate in situ observations during those times when energy transfer is most active. It is at these times that spaceborne SAR provides views of the sea surface that are difficult or impossible to obtain by any other means. SAR imagery has proven its utility in locating small severe storms like polar mesoscale cyclones. These storms can have winds of hurricane force, but occur in regions with little in situ data and which are obscured from visible/IR satellite sensors by clouds. SAR provides $1 \mathrm{~km}$ or better wind resolution and does so even relatively close to the shore. Even if there is a uniform cloud deck obscuring a storm, SAR imagery penetrates the clouds to show the location of the center of the storm at the sea surface, the position of highwind fronts, swell direction and wavelength, and the general morphology and extent of the storm. Even when the visible and infrared satellite imagery does show the storm features, then the SAR imagery of wind patterns at the ocean's surface complements the information on winds and fronts at the top of the clouds derived from the visible/IR imagery, to reveal aspects of the three-dimensional structure of the storm. Recently, SAR imagery has been employed in hurricane studies of eye morphology, location of rain bands, convection cells, high-resolution wind patterns, and roll vortices (see Figure 5).

The most important SAR characteristics for oceanography are all-weather opera- tion, wide swath measurement, dual polarization capability, and daily to weekly observation schedules. Coastal zone observations are especially desired since the highly dynamic region between the coast and the edge of the continental shelf is critical to many facets of our society, including coastal infrastructure, fishing, boating, shipping, and offshore oil interests.

In coastal regions, NOAA has demonstrated the potential of SAR as a means of monitoring and alerting maritime traffic and low-flying aircraft to strong wind events such as gap winds, down-slope winds, and barrier jets. To be used operationally, however, the frequency of coverage must be much greater than is currently available. The wide-swath, left-right looking, and dual satellite features of Option 5 in the Ocean Observer concept could be an important step in this direction; although even then the frequency of coverage is still not optimum. Imaging SAR instruments are unique in their ability to measure winds close to the coast and even in bays, rivers, and lakes. There is no contamination of the signal by adjacent land such as that which occurs in scatterometer and microwave radiometers.

Along-track SAR interferometry has been shown to be able to measure coastal currents, an application important for search and rescue, fishing, marine transportation, and naval applications. SAR has also demonstrated its ability to detect and track both anthropogenic and natural oil slicks. This ability is especially useful in the enforcement of pollu- 
tion laws since a SAR can monitor dumping day and night during a wide range of weather conditions. This is a critical capability since most large oil spills at sea occur as a result of severe weather. Oil slick tracking is also of great importance in the containment of oil spills. Winds derived from SAR data can provide local wind conditions for use in oil spill trajectory models.

Norway has demonstrated the operational usefulness of SAR imagery for the monitoring of illegal oil dumping and bilge pumping from vessels underway. The utility of SAR has also been demonstrated in detecting of vessels at sea for the enforcement of national maritime borders, exclusive economic zones, and fishing regulations. Violation of environmental and resource regulations often occur in cloud covered conditions, far from land when enforcement capability and optical tracking are least effective. Using a SAR along with Vessel Monitoring Systems that report the location of licensed fishing vessels, would allow enforcement agencies to discriminate between legal and illegal vessels.

\section{SAR Application - Cryosphere}

All-weather SAR imaging of the high latitude seas provides information which is vital to minimizing the hazard in maritime activities in ocean areas covered with sea ice (or iceinfested sea areas). Monitoring sea ice also provides important information on climate trends such as the reported interannual loss of ice cover in the Arctic Ocean. Airborne tracking of icebergs and ice cover is expensive, risky, and limited in scope due to weather, range, and budgets. Satellite ice tracking utilizing SAR imagery has been amply demonstrated and is quickly becoming the accepted technique. The National Ice Center, a multi-agency operational center representing the Navy, NOAA, and the Coast Guard, is now totally dependent upon Canadian and European SAR satellites for its radar data.

Sustained development of coastal areas worldwide has made the global economy extremely vulnerable to changes in sea level. Ice sheets and mountain glaciers contain a frozen reservoir totaling nearly $80 \%$ of the world's fresh water and are the primary source of future sea level rise. SAR, and specifically InSAR, is an important new tool to precisely measure the volume and dynamics of our glaciers and ice caps though they are often shrouded in clouds. The radar techniques applied are very similar to those used in the measurement of land topography and the motion along faults as described earlier.

Surface topography determines the magnitude and direction of the gravitational force driving the ice flow. Therefore the detailed topography of the ice sheet determines the boundaries of individual drainage basins contained within the ice sheet. In addition, the undulating character of the ice-sheet surface provides proxy evidence for whether the ice flow is dominated by ice sliding over a welllubricated bed, or whether the ice is frozen to the sub-glacial terrain. Finally, the complete elevation field can be an invaluable aid to the interpolation of laser altimetry which inherently only measures elevations along very narrow corridors across the ice sheet.

Ice velocity is the fundamental parameter representing the dynamics of ice. It can be compared with "balance" velocities determined from aerial integration of the snow accumulation to assess the state of equilibrium of any ice mass, or portion of an ice mass. Even in the absence of accumulation data, the magnitude and direction of ice flow is critical input to dynamic models of ice flow and, when compared with surface topography, can identify regions that are far from equilibrium.

SAR holds the advantage of viewing through clouds that are frequently persistent at the edges of ice sheets and in mountainous terrain. The InSAR technique is building an unprecedented series of snapshots documenting the short-term evolution of ice sheets. This objective is particularly germane given the recent and unexpected disintegration of large portions of ice shelves in the Antarctic Peninsula and the implied consequences of climate change to coastal communities. Using the Canadian RADARSAT-1, NASA is periodically imaging the entire Greenland and Antarctic Ice Sheets.

The high resolution and cloud-penetration capabilities of SAR have made it a particularly useful tool in monitoring spring breakup of major rivers in northern regions (e.g., Yukon in Alaska and Yellowstone in Montana). Onset of breakup, ice runs, ice jams, and flooding due to ice jams have all been monitored with ERS-2 and RADARSAT-1 SAR imagery.

\section{SAR Application-Water Management}

Results of recent experiments demonstrate the utility of SAR for the management of water resources. The timely and uniform measurement of mountain snow pack and glacier dynamics is as important to water resource management as it is to disaster mitigation.

Recent research has demonstrated the ability to use InSAR to measure surface subsidence and rebound in response to aquifer discharge and recharge in regions such as Los Angeles, Las Vegas, Houston and other cities dependent upon subsurface water. The USGS and NASA are investing significantly in the 
development of SAR technology to advance the remote measurement of land subsidence as a proxy for aquifer change.

Soil moisture is an environmental descriptor that integrates much of the land surface hydrology and is the interface for interaction between the solid Earth surface and life. As central as this seems to the human existence and biogeochemical cycles, soil moisture has seen little application in land process models because soil moisture is difficult to measure on a consistent and comprehensive regional basis. Point measurements have very little meaning because soil moisture exhibits very large spatial and temporal variability. Therefore, it has been impractical to include soil moisture in current hydrologic, climatic, agricultural, biogeochemical, or fire hazard models despite the acknowledged importance of these measurements. Frequent and accurate synoptic measurement of soil moisture is the single most significant weather-related variable needed by USGS and NOAA. It is likely that polarimetric SAR imaging of large areas may be successfully applied to the measurement of soil moisture. Soil moisture variations change the ground surface conductivity and therefore the characteristics of reflected SAR signals. Polarimetric SAR could be used to separate the effects of changes in soil moisture from changes in biomass and surface roughness.

Satellite imaging in the visible portion of the spectrum is widely used to map extent of snow-cover. Snow cover data are incorporated into operational snowmelt forecasting schemes, but the snow-covered area may not be a reliable indicator of the amount of water stored in the snow pack. A fundamental property of snow required for the forecasting of water supply is the snow-water equivalence, the amount of water that can be obtained from the melted snow. Traditionally this variable is measured at several hundred snow courses throughout the mountainous regions of the western United States. This measurement is of limited value. There remains a need to develop a higher resolution estimate for the spatial distribution of snow-water equivalence over entire basins. The measurement snow-water equivalence in snow pack can be done with dual-polarization L-band SAR data to estimate snow density and higher frequency SAR data to estimate snow volume.

With more accurate estimates of snow volume, detection of melting snow, and the measurement of the spatial distribution of snow-water equivalence, we will be able to better forecast melt on short and season-long time scales. Such forecasts will improve the management of reservoirs in areas of snowmelt runoff, and thus improve the allocation of water for agriculture and other uses.

\section{SAR Application - Floods}

InSAR is an effective tool in the mapping of snow pack, the accurate measurement of water level changes in river valleys and wetlands, the estimation of soil moisture and the delineation of topography for catchment basins and flood plains. All weather SAR images can track the migration of rising flood waters in support of disaster response efforts. Post-flood images can be used to assist in quantitative damage assessment, and for rapid damage assessment during the immediate post-flood period when the area may still be cloud covered.

SAR images can also serve in rapid damage assessment after major hurricanes, when cloud cover and damaged infrastructure (telephones, roads, bridges) make conventional surveys difficult. Sequences of InSAR images could detect weakness in the overburden in landslide-prone areas as an early sign of incipient ground failure. InSAR can also measure surface change caused by human activity. Uncontrolled subsidence can lead to higher flood potential and other risks to infrastructure. Land erosion carries away significant amounts of precious topsoil and chokes our rivers and coastal zones. High precision SAR-generated topographic maps can identify with great precision those regions that are loosing soil due to erosion.

\section{SAR Application - Earthquakes}

The most challenging goal for InSAR is mapping slow Earth deformation. This includes the interseismic accumulation of strain leading up to earthquakes, as well as transient postseismic strain relaxation following earthquakes. Scientists supported by NASA, the USGS, and the NSF are seeking repeated measurement of surface change in seismically active areas along the Earth's plate boundaries. This is where the highest probability of earthquakes exists. From this new knowledge will come better estimates of earthquake hazards. The scientific community and the National Research Council have repeatedly endorsed the use of InSAR to advance our understanding of the earthquake cycle (see Figure 6). InSAR is a space geodetic imaging technology, which enables the precise measurement of surface deformation over large regions before, during, and after earthquakes. InSAR observations are leading to a revolutionary change in our understanding of the slow changes in the Earth surface that build the forces released in earthquakes.

SAR can also serve in earthquake disaster response by providing regional high-resolution information for the assessment of both risk and damage to critical infrastructure including buildings, dams, aqueducts, highways, 
Figure 6. Earthquake Change Mapping. This image is an interferometric map of the Landers, 1992 earthquake area showing the ground displacement along the radar line of sight. One full color cycle represents here $5 \mathrm{~cm}$ of range displacement. Gray areas are zones of low phase coherence that have been masked before unwrapping. Solid lines depict the 1992 surface rupture.

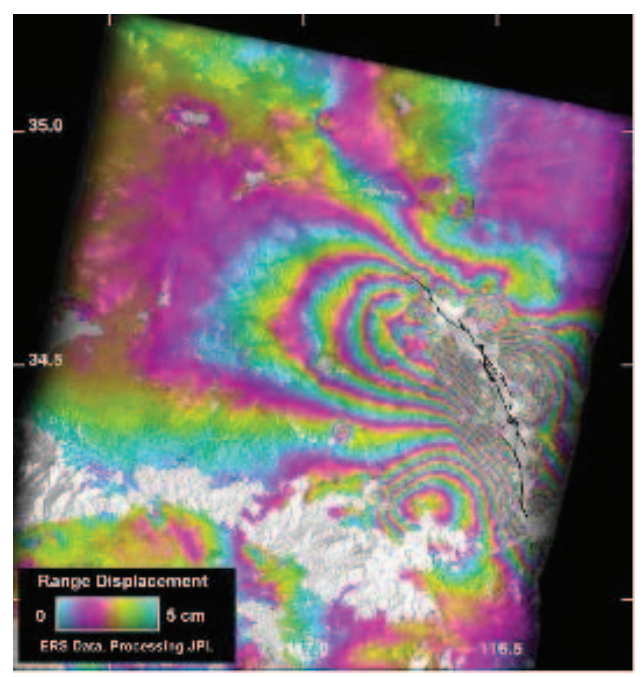

bridges, and sewer/gas lines. This SAR based all-weather damage assessment capability can complement information available from local observing systems such as leak detectors, strong motion seismic networks, or emergency response teams.

\section{SAR Application - Volcanic Eruptions}

Interferometric analysis of multiple SAR images of volcanoes revealed that a number of U.S. volcanoes previously thought to be dormant or inactive are in fact actively changing shape in response to the movement of magma and gases beneath the volcano.

Sequences of InSAR images for Etna (in Italy) and Okmok and Westdahl (in Alaska) dramatically demonstrate the inflation of the volcano's surface preceding an eruption. InSAR data provides an important new capability to define both the long-term and near-term risk to our citizens and our infrastructure from volcanic hazard. Combined with ground-based seismic, GPS, and gas monitoring, InSAR data can provide important new remote warning capabilities to help mitigate disasters such as the 2002 loss of 147 lives and 12,000 homes to the sudden fissure eruptions at Nyiragongo Volcano in the Democratic Republic of Congo or the 1985 Lahars eruption which claimed approximately 23,000 lives in the village of Armero, at the foot of Nevada del Ruiz Volcano in Colombia. There are the more than 100 potentially explosive volcanoes along the air routes from the U.S. to eastern Asia. The addition of all weather InSAR measurement of the Aleutian, Kamchatkan, and
Kurile volcanic chains to existing monitoring from weather satellites and ground-based instruments will further reduce risk of volcanic ash clouds to our aircraft which fly these busy North Pacific jet routes.

\section{SAR Application - Biomass}

The all-weather capability of SAR imaging offers great promise for the measurement of biomass or fuel load in the management of fire hazard and as an automated technique in support of fire fighting and controlled burns. Polarimetric InSAR is being used to develop operational approaches for addressing patterns of deforestation and forest regrowth, and their contribution to the global carbon budget. Polarimetric SAR techniques can be used to estimate biomass because the signals change polarization as they bounce between ground and the overlying vegetation.

Unfortunately, the dearth of SAR data has impeded its development as a wide area surveying technique.

Wildfire is a major cause of property loss and habitat degradation. The sensitivity of SAR data to above-ground biomass can be used to improve estimation of the available fuel loads and may prove useful in developing strategies to reduce risk through management practices such as thinning. In addition, SAR data can be used to enhance the assessment of wildfire risk and the impact of wildfire on subsequent erosion and land sliding. Studies in Alaska have taken advantage of the sensitivity of SAR to the dryness of the fuel load and thereby improve upon traditional methods, based solely upon weather stations to provide spatially explicit mapping of fire hazard. Such products could be of great value to the allocation of fire fighting resources.

Land cover change is one of the fundamental factors in resolving the global carbon cycle. In addition to identifying primary land conversion, successful efforts are underway using SAR to estimate regrowth in secondary forests, a key factor in carbon balances. These efforts could allow the measurement of forest regeneration in the worldwide belts of tropical, temperate, and boreal forest at yearly intervals over at least a three-year period.

Notwithstanding the burning of fossil fuels, worldwide deforestation and forestation practices are believed to have the highest impact on the net flux of greenhouse gases and carbon management. Monitoring the changes in biomass provides a critical piece of information in understanding the global carbon cycle, since carbon is stored in the form of biomass in forests, which is interdependent with factors such as nutrient fluxes, water availability, age of forest, and temperature. 
Figure 7. Left: Aircraft imagery at 550nm of the New Jersey coast, subsampled to $800 \mathrm{~m}$ resolution to simulate VIIRS. It inadequately defines coastal features of the Mullica River estuary. Right: Aircraft imagery at $550 \mathrm{~nm}$ of the New Jersey coasts subsampled to $100 \mathrm{~m}$ spatial resolution to simulate the Ocean Observer. The details of the coastal features are adequately defined.
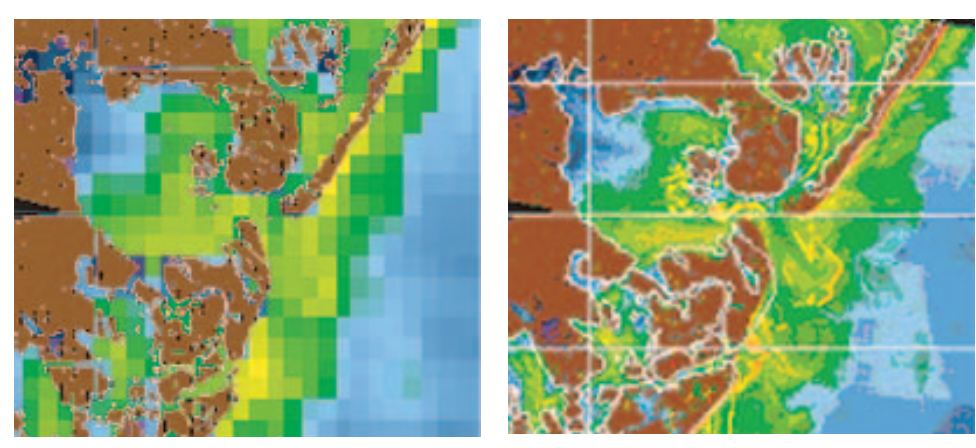

\section{VISIBLE/INFRARED IMAGING SPECTROMETER}

\section{Rationale}

Visible and infrared imaging has been the mainstay of atmosphere, land, and ocean remote sensing since the 1970 s, for both the military and civilian sectors. Meteorologists use visible and thermal imagery to track cloud distributions, and these images are featured regularly on the evening news. The Advanced VeryHigh Resolution Radiometer (AVHRR) on the current NOAA polar orbiting satellites has been providing valuable data for meteorology, Sea Surface Temperature (SST), and global vegetation studies for more than two decades. More recently, as part of its Earth Observing System program NASA built the Moderate Resolution Imaging Spectroradiometer (MODIS). MODIS has 36 spectral channels compared to five for AVHRR. Nine of these channels are narrow spectral channels for ocean color measurements. These channels are based on experience with the Coastal Zone Color Scanner (CZCS; 1978-1986) and more recently with the Seaviewing Wide-Field of View Sensor (SeaWiFS), which was launched in 1997. The key measurement for the open ocean is the abundance and productivity of phytoplankton, the single-celled plants that are the base of the marine food chain. Water is highly absorbing, and phytoplankton pigments absorb the remaining available light for photosynthesis, further reducing the reflected light. This dark ocean target requires a set of narrow, high-sensitivity spectral channels to correct for atmospheric effects and resolve the spectral signals used to estimate phytoplankton abundance. MODIS and SeaWiFS have the required channels and have provided data that have been critical to estimating global ocean phytoplankton biomass and production and the role of the ocean in the global carbon cycle.

The Visible Infrared Imaging Radiometer Suite (VIIRS) is the operational follow-on to MODIS. It will replace the AVHRR, providing global coverage with an $800 \mathrm{~m}$ resolution at nadir. VIIRS will be a valuable tool for global ocean SST, phytoplankton and carbon cycle measurements, and continental scale estimates of land biomass and production. However in the coastal ocean, higher spatial resolution is required (see Figure 7) to deal with the spatial complexity and to match the resolution of the dynamical models being developed by the Navy and NOAA for these regions. Current high-resolution optical sensors, such as Landsat's Thematic Mapper (TM) and high resolution commercial systems, are not well suited for ocean imaging. These systems have a moderate Signal-to-Noise Ratio (SNR) and 4 to 6 broad spectral channels designed for the brighter land signals. Because of the spectral properties of water and phytoplankton absorption, and the fact that water is a very dark object, these land sensors do not work well for coastal ocean applications.

Imaging spectrometers typically have 60 or more spectral channels and provide continuous spectra for each pixel in the scene. This high spectral information is essential for resolving the complexity of the coastal ocean. High sensitivity airborne imaging spectrometers, such as NASA's Airborne Visible/Infrared Imaging Spectrometer (AVIRIS) have been used for the past decade to retrieve water-column optical properties, bottom type and bathymetry products. This experience is the basis for the proposed instrument design and the product algorithms that will be used with that system

The coastal environment is more complex optically than the open ocean. River and land runoff, resuspension of sediments during storms, red tides, and pollution all add to the range of optical properties that need to be resolved in the coastal ocean. In shallow waters, visible remote sensing systems frequently image the bottom including features such as sea grass beds and coral reefs. Resolving the bottom features as viewed through the complex and varying optical properties of the water column is the central problem in coastal remote sensing which requires imaging spectrometry. The depth from which the sensor receives a signal from the bottom varies as a function of wavelength, the clarity of the water and the sensitivity and SNR of the sensor. Absorption by the water itself limits the depth of penetration for the longer wavelengths, while absorption by Colored Dissolved Organic Matter (CDOM) and phytoplankton are the primary factors limiting light penetration in 
the blue. In the clearest waters, the bottom is detectable at 30 meters and imaging spectrometers can provide useful shallow water bathymetry to 15 meters for many clear water environments.

The U.S. Navy is in the midst of a fundamental shift away from open ocean warfare on the sea towards joint operations from the sea. To support that effort, the Navy and Marine Corps need better methods for determining shallow water bathymetry, topography, bottom type composition, detection of underwater hazards, water clarity and visibility. Visible radiation is the only electromagnetic tool that directly probes the water column, and is key to naval systems for bathymetry, mine hunting, submarine detection, and submerged hazard detection. The Navy needs dynamical models to forecast optical properties at resolutions of $100 \mathrm{~m}$ or better for the near coastal ocean. A hyperspectral sensor with $100 \mathrm{~m}$ or better spatial resolution is required to provide essential data for the development, initialization, and updating of these models.

NOAA is leading the development of the Coastal Global Ocean Observing System (CGOOS) to monitor the health of the coastal ocean, including providing warnings of harmful algal blooms, assessing changes in water clarity, biodiversity and the growth of non-indigenous species. A $100 \mathrm{~m}$ spatial resolution, 10 nanometer spectral resolution hyperspectral sensor will provide the synoptic view to complement the planned mooring and ship-based measurements, and will give a coherent picture of the coastal ocean. The $100 \mathrm{~m}$ resolution is 8 times that of the current global ocean color imagers $(10,000$ sq. meters compared to $1,000,000$ sq. meters per pixel) and sufficient to image red tides, fronts, bays, estuaries and other features of concern for coastal management while still providing a broad $200 \mathrm{~km}$ wide swath along the coast.

\section{Instrument}

A moderate resolution hyperspectral imager (imaging spectrometer) is proposed for characterization of the coastal ocean. The instrument, designated the Coastal Ocean Imager (COI) would have $64,10 \mathrm{~nm}$ wide spectral channels covering the 380 - $1000 \mathrm{~nm}$ spectral range. Recent improvements in array detectors make it possible to extend down into the ultraviolet range to $380 \mathrm{~nm}$ to detect signatures of oil spills and red-tide dinoflagellates. A scanning telescope on board would allow it to follow the coastline and sweep a $200 \mathrm{~km}$ wide swath that tracks the coast. With a +/ $45 \mathrm{deg}$ field of regard, a 2-day revisit to any coastal region would be possible as would obtaining data co-registered with the SAR data. In addi- tion two channels in the thermal infrared would measure SST at the same $100 \mathrm{~m}$ resolution. The SST channels and algorithms would be the same as VIIRS so that the high-resolution data would merge seamlessly with the global SST from VIIRS. This could be a compact instrument using proven designs and already space-qualified components to minimize cost. This high resolution system would make the Ocean Observer a valuable system for the coastal ocean and for optical and biological applications essential to Navy and NOAA missions.

\section{Application - Regional High Resolution Weather Impacted Imagery}

There is a DoD and DOC requirement for imagery of sufficient resolution to discern major land and ocean features in the coastal region and separate them from cloud types. COI would provide this imagery at $100 \mathrm{~m}$ resolution in all spectral channels. All other coastal products are derived from this imagery.

\section{Application - Shallow Water Bathymetry}

Visible radiation is the only electromagnetic tool that directly probes the water column, and thus is key for measuring shallow water bathymetry. Visible radiation penetrates the water up to $30 \mathrm{~m}$ under clear conditions and can give bathymetry measurements to 10 meters (30 ft) for many coastal conditions. The high spatial and spectral resolution and SNR of COI are essential for this measurement.

\section{Application - Coastal Ocean Color}

Ocean color is defined as the spectrum of water-leaving radiances (Lw), i.e. the portion of visible-near infrared light that is reflected back out of the water column, excluding light reflected at the surface. All geophysical quantities of interest, e.g., chlorophyll-a and ocean optical properties, are derived from these Lw values. COI would provide these data for selected lakes, rivers, estuaries, bays, and other coastal regions that require higher resolution data. The coastal resolution specified has been shown to be essential for imaging lakes and rivers, and many typical coastal areas, bays and estuaries that have spatial scales of one to a few kilometers (see Figure 5). Lakes, rivers and coastal regions possessing features with high gradients demand higher resolution observations than the $1 \mathrm{~km}$ resolution provided by VIIRS. Derived parameters are required at this resolution for coastal dynamics (modeling), human health (drinking water quality, red tides, pathogens), oil spill response, aquaculture, and fisheries management. Ocean color measurements and derived EDRs are required at the 
same resolution as regional and coastal SST measurements.

\section{Application - Coastal Ocean Optical Properties}

Chlorophyll fluorescence and the inherent optical properties of absorption and scattering of surface waters can be estimated from ocean color imagery. Absorption and scattering are estimated at each measured visible wavelength, and all properties have units of inverse meters (m-1). This EDR is relevant for clear daytime conditions only, for selected lakes, rivers, bays, estuaries, and other coastal regions that require high-resolution data.

Ocean optical properties are derived from ocean color water-leaving radiances. The surface optical properties of total absorption (at) and total backscattering (bbt) at specific wavelengths can be determined from the remote sensing reflectance. Absorption and backscattering can be broken down into additional optical properties. Phytoplankton pigment absorption is used to calculate chlorophyll concentration. Non-phytoplankton absorption (e.g. colored dissolved organic matter, and detrital absorption) is required for characterization of river plumes, as a surrogate for salinity, and for understanding of the water quality factors determining light availability (separating phytoplankton from detrital impacts). Backscattering is used to calculate the amount of particulates in the water. The spectral properties of absorption and scattering combined are used to separate phytoplankton, detritus and inorganic particulate matter components in the water. For example of algorithms see the MODIS theoretical basis documents at http://modis.gsfc.nasa.gov/data/atbd/ocean_atbd.html. These properties are also employed for detecting and characterizing river plumes, modeling the distribution of pollutants in coastal waters, estimating salinity, calculating phytoplankton primary production, and evaluating seagrass and coral health.

The Fluorescence Line Height (FLH) algorithm is a relative measure of the amount of radiance leaving the sea surface, which is a result of chlorophyll fluorescence. By constructing a baseline using bands on either side of the fluorescence band, it is possible to estimate the deviation from the amount of radiance expected for pure water that results from chlorophyll fluorescence. This increase in radiance (centered at $683 \mathrm{~nm}$ for chlorophyll) has been noted for decades in measurements of the light field in the ocean.

Chlorophyll fluorescence is a measure of the light-harvesting pigments of phytoplankton. The amount of fluorescence is a complicated function of light capture by chlorophyll and the rate of photosynthesis. Much attention has focused on the use of fluorescence to estimate chlorophyll concentrations in the presence of suspended particulate and dissolved material, and to estimate primary productivity. Measurements of chlorophyll fluorescence from space provide 1) an alternative to absorptionbased chlorophyll algorithms which may fail in turbid and coastal waters, and 2) an estimate of the photosynthetic "health" of phytoplankton.

\section{Applications - Bioluminescence Potential}

Bioluminescence potential represents the probability of eliciting a detectable flash of light by disturbing light-producing organisms within the ocean. It is measured from ships by pumping water through a darkened chamber where the plankton are agitated and the bioluminescent signal is recorded. This potential results from a complex interplay between the abundance (as estimated by chlorophyll) and taxonomic composition of organisms in the surface layer, ambient light level, and sea surface temperature all of which are measured at the same time. Estimates of bioluminescence potential from satellite data are made based on a regression of the measured bioluminescence potential against chlorophyll with correctors for temperature and other environmental factors. High levels of bioluminescence can indicate the presence of boats, swimmers or other objects moving through the water at night. This is a DoD requirement for coastal waters.

\section{Application - Littoral Sediment Transport}

The transport of sediment by river systems and along-shore currents may be computed by estimating the concentration of sediments from the COI data and estimating the coastal and river currents from SAR data or coastal current models. This approach requires a model estimate of the vertical distribution of sediments in the water column. It is expected to give approximate or relative transport values, but these estimates will be valuable for issues related to harbor dredging and beach preservation and restoration.

\section{Applications - Coastal SST}

Sea Surface Temperature (SST) is defined by NOAA as the temperature of the surface layer (upper 1 meter) of ocean water based on regression of satellite data against NOAA buoy data. It is measured using two thermal infrared channels in the 10-12 micron range and algorithms similar to those for AVHRR, MODIS and VIIRS (e.g. see the MODIS theoretical basis document at http://modis. gsfc.nasa.gov/data/atbd/ocean_atbd.html). SST 
has three major applications: 1) sea surface phenomenology, 2) use in infrared cloud/no cloud decision for processed cloud data, and 3) as an input to coastal ocean dynamic models. The requirements below apply only under clear conditions for selected lakes, rivers, and coastal regions that require high-resolution data, which yield high-resolution measurements of SST in limited regions. SST measurements in bays, rivers, estuaries, lakes, and near shore regions, when paired with coastal ocean color, chlorophyll, and optical properties, allow analysis of the dynamics of coastal areas, for water quality monitoring, oil spill response, support to aquaculture, and fisheries management. High resolution SST is a key parameter for the development, initiation, and validation of models of coastal ocean dynamics.

\section{Application - Ice Surface Temperature}

Similar to SST, ice surface temperature is measured using the thermal infrared channels. The temperature at the ice surface is an EDR but can only be measured under clear conditions. Ice Surface Temperature should be calculated at the full resolution of the imager so that temperatures in small leads and polynyas can be measured. Regional coverage over all ice-covered ocean regions of the globe and the Great Lakes is required. The data are used in combination with the SAR ice cover and ice type data to predict the formation or melting of ice.

\section{Application - Vegetation Classification/Biomass}

Imaging spectrometer data is especially valuable for the classification of vegetation when used in combination with the SAR data. The SAR provides information on vegetation height and the water content of the vegetation. The spectral data provides information on plant type and health. For example, AVIRIS data for cropland in Colorado was used to classify the crop type by the unique spectral signature of the plant and crop health by looking for pigment changes due to shortage of nutrients or water (Clarke, et al., 1995, http://speclab.cr.usgs.gov/PAPERS.veg1/vegispc2.html). These data may be used for regional crop assessments, fire hazard assessment, invasive species and other ecological issues.

\section{SUMMARY}

TPOESS is the future operational satellite 1 system for the U.S. and its current empha- sis is on weather and land observations. It is being managed by the Integrated Program Office (IPO), which is comprised of NOAA, DoD, and NASA (who build and operate the current U.S. government satellite systems). The IPO performed a study to determine what requirements were not currently in the NPOESS program, but which are still needed by the U.S. operational satellite observation community. The study was known as the Ocean Observer Study (OOS). The study first determined the user requirements which were then translated into instrument designs and finally into a mission design. The mission design included the required instruments, the required orbits, the spacecraft, and the ground segment. The needed instruments identified were an altimeter, a visible/infrared imaging spectrometer, and a SAR. The observations dealt with oceans and land. The sensors chosen serve to meet the requirements for which the U.S. community expressed a need.

If funded, the NPOESS IPO already has in place the infrastructure required to develop, manage, and operate this proposed new mission. The mission would further benefit from the active ties with the foreign community that has been established by the IPO. The NPOESS ground system could be used to also support this additional mission. That ground system will have 15 ground stations distributed around the world, and which will be linked by a fiber network that is already in place. Similarly, the NPOESS data communication centers can also serve this mission. Finally, a thorough competitive process resulted in selecting a contractor to establish a production line for NPOESS spacecraft that would also be appropriate for the OOS mission.

\section{ADDITIONAL READING}

1) Chambers, D. P., 1996. Time-varying sea surface topography from satellite altimetry. Rep. CSR-96-04. Austin, Texas: Center for Space Research.

2) Synthetic Aperture Radar: An Essential Tool for Disaster Reduction and Maintenance of our National Resources. A White Paper of the Subcommittee on Disaster Reduction, (Submitted July 11, 2003).

3) NPOESS Integrated Operational Requirements, Document-II. http://npoesslib.ipo.noaa.gov/Req_Doc/IO RDII_011402.pdf. 